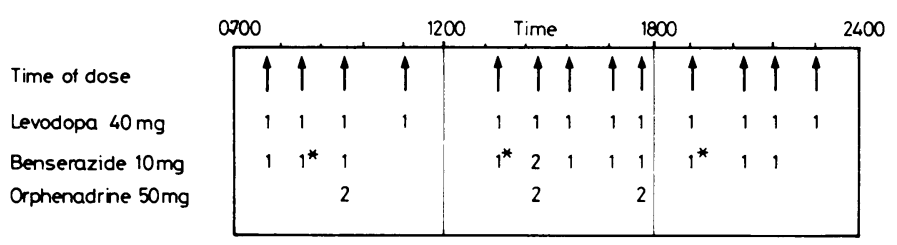

Regimen established to provide smoothest effect, showing number of capsules of each drug taken. A total of $520 \mathrm{mg}$ levodopa and $120 \mathrm{mg}$ benserazide a day was required.

* Mealtime.

effect of a dose of levodopa could be enhanced by doubling the dose of benserazide given with it from 10 to $20 \mathrm{mg}$, but separating the doses by more than 45-60 minutes usually abolished this effect.

By a process of trial and error the regimen shown in the figure was adopted. Levodopa was taken in doses of $40 \mathrm{mg}$ at intervals of half an hour to two and a half hours during the day. Most doses were accompanied by $10 \mathrm{mg}$ benserazide. Levodopa was given alone in the late morning and on retiring, since combining it with benserazide at these times caused chorea. Additional benserazide was required one hour after lunch to avoid an akinetic spell in the afternoon. Orphenadrine $50 \mathrm{mg}$ was given twice daily, and the timing of its doses did not appear to be critical. With this regimen the patient could take daily walks with her husband and help with shopping for the first time in two and a half years. Her gait remained highly abnormal, with bizarre athetoid movements of the right leg. Bradykinetic spells occupied about three hours of each waking day, usually in the early morning, after lunch, and in the early evening. Appreciable chorea, during which she could remain in her chair, occupied about two hours a day, mainly around 1130-1230 and 1630-1730, and could be provoked by delaying a meal.

\section{Discussion}

This patient's performance was greatly improved over a period of nine months by treating her with frequent small doses of benserazide and levodopa given separately. We observed that levodopa in the doses used was ineffective if given by mouth more than one hour before or one hour after a dose of benserazide irrespective of the degree of decarboxylase block in the peripheral tissues. Furthermore, coadministration of the same dose of levodopa with benserazide led to chorea, suggesting overdosage of levodopa.

The observations made in this patient are consistent with the view that the "on-off" syndrome is related to changes in levodopa concentrations and that the syndrome may be managed better by giving frequent small doses of levodopa and benserazide. Two clear factors emerge from this case report. Firstly, blocking local gut decarboxylase activity at the time of administration of levodopa is more important than peripheral blockade, and, secondly, absorption of levodopa is affected by food intake. This might result from stimulation of local gut decarboxylase activity or from changes in the rate of gastric emptying.

The four to one ratio of levodopa to benserazide appears to be appropriate for general use, and patients with brittle disease might be managed by frequent administration of Madopar 62.5 (50 mg levodopa and $12.5 \mathrm{mg}$ benserazide) with small doses of levodopa or benserazide added to the regimen to obtain the "fine tuning" required. Further work is planned to validate these findings.

(Accepted 14 fanuary 1982)

\title{
Nicotine concentrations in urine and saliva of smokers and non-smokers
}

\author{
COLIN FEYERABEND, TIM HIGENBOTTAM, M A H RUSSELL
}

\begin{abstract}
Nicotine concentrations were measured in saliva and urine samples collected from 82 smokers and 56 nonsmokers after a morning at work. Each subject answered a series of questions related to their recent intentional or passive exposure to tobacco smoke.

All non-smokers had measurable amounts of nicotine in both saliva and urine. Those non-smokers who reported recent exposure to tobacco smoke had significantly higher nicotine concentrations $(p<0.001)$ than those who had not been exposed; their concentrations overlapped those of smokers who had smoked up to three cigarettes before sampling. Among the cigarette smokers, the number of cigarettes smoked before sampling had the greatest influence on nicotine concentrations $(r=0.62$ for saliva and $\mathbf{r}=0.51$ for urine). Neither the nicotine yield of cigarettes nor the self-reported degree of
\end{abstract}

\footnotetext{
National Poisons Unit, New Cross Hospital, London SE14, and Addiction Research Unit, Institute of Psychiatry, Maudsley Hospital, London SE5

COLIN FEYERABEND, BSC, senior biochemist

TIM HIGENBOTTAM, BSC, MD, MRCP, (consultant physician, chest unit, Addenbrooke's and Papworth Hospitals, Cambridge CB2 2OQ)

M A H RUSSELL, MRCP, FRCPSYCH, senior lecturer
}

inhalation had any significant effect on nicotine concentrations.

\section{Introduction}

For many years estimates of exposure to tobacco smoke have depended on information from questionnaires. More recently biochemical indices of smoke inhalation have been introduced ${ }^{1-3}$; nicotine, being specific to tobacco smoke, provides a direct measure of smoke intake. Although peak nicotine concentrations just after smoking have a short half-life in blood, there is some accumulation and trough concentrations tend to build-up during the day. ${ }^{4}$ This suggests that salivary and urinary nicotine concentrations could be a useful non-invasive measure of exposure to tobacco smoke. Previous studies have concentrated on quantifying smoke intake among cigarette smokers, but smokers are not the only people to be exposed to smoke. Nonsmokers may passively inhale other people's tobacco smoke and so develop small airway disease ${ }^{5}$ or be at greater risk from lung cancer compared with non-exposed non-smokers. ${ }^{6}$

We have compared the intake of tobacco smoke of smokers with that of two groups of non-smokers. One group had been exposed to smokers during their normal morning's work, the other had not. Exposure to tobacco smoke was assessed by a questionnaire and by measuring nicotine concentrations in saliva and urine. 


\section{Subjects and methods}

Sampling technique-Fifty-six lifelong non-smokers and 82 smokers took part in the study. Each provided a sample of urine and saliva (average time about $1200 \pm S D$ two hours and 35 minutes) and completed a questionnaire. The subjects included laboratory, medical, and dental staff as well as outpatients at New Cross Hospital. The volume and $\mathrm{pH}$ of each sample and the time at which the sample was

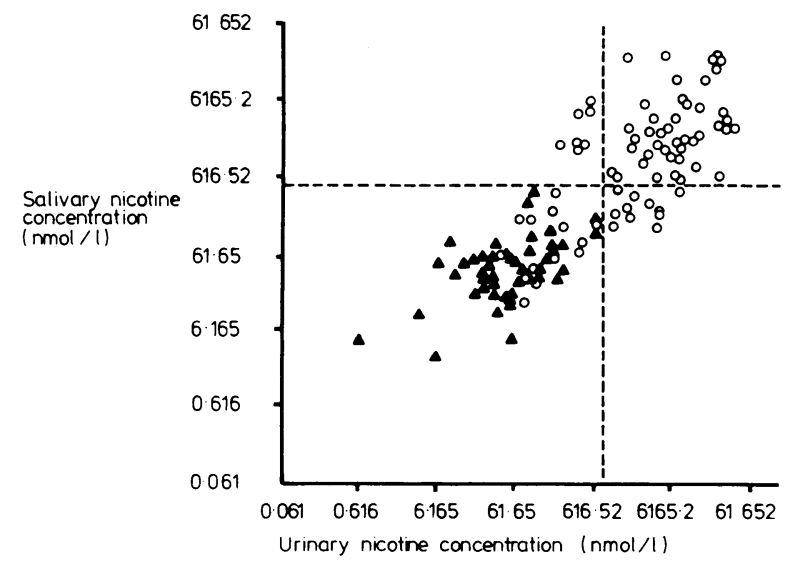

FIG 1-Correlation between salivary and urinary nicotine concentrations: for all subjects, $r=0.84$; for smokers alone, $r=0.62$; and for non-smokers, $\mathbf{r}=0.04$. Symbols denote: $\Delta-$ Non-smokers, $\bigcirc-$ smokers.

Conversion: SI to traditional units-Salivary and urinary nicotine: $1 \mathrm{nmol} / 1$ $\approx 6.2 \mathrm{ng} / \mathrm{ml}$.
Statistical analysis-A step-wise multiple regression ${ }^{8}$ was performed to estimate the influence of these factors on the measured nicotine concentrations. Data from non-smokers were analysed separately. Values of nicotine concentration were logarithmically transformed to stabilise their variance. ${ }^{9}$ Analysis of variance was used for comparisons between smoking and non-smoking groups.

TABLE I-Stepwise multiple regression for cigarette consumption, nicotine yield of cigarettes, and other variables from a self-administered questionnaire with $(A)$ urinary nicotine and $(B)$ salivary nicotine as the dependent variables

\begin{tabular}{|c|c|c|c|c|}
\hline Independent variables & $\underset{\mathbf{R}}{\text { Simple }}$ & $\begin{array}{c}\text { Stepwise } \\
\text { multiple } \\
\mathbf{R}\end{array}$ & $\begin{array}{c}R^{2} \\
\text { change }\end{array}$ & $\begin{array}{c}\text { Statistical } \\
\text { significance }\end{array}$ \\
\hline $\begin{array}{l}\text { (A) } \\
\text { Number of cigarettes before sample } \\
\text { Minutes since discarding cigarette } \\
\text { pH of urine } \\
\text { Nicotine yield of cigarette } \\
\text { Daily cigarette consumption } \\
\text { pH of saliva } \\
\text { Salivary nicotine concentration } \\
\text { Number of cigarettes in last hour } \\
\text { Minutes since last drink } \\
\text { Duration of smoking habit } \\
\text { Volume of urine sample } \\
\text { (B) }\end{array}$ & $\begin{array}{r}0.514 \\
-0.656 \\
-0.484 \\
0.226 \\
0.455 \\
-0.268 \\
0.621 \\
0.386 \\
0.213 \\
0.313 \\
0.221\end{array}$ & $\begin{array}{l}0.514 \\
0.700 \\
0.829 \\
0 \cdot 839 \\
0 \cdot 841 \\
0.848 \\
0.852 \\
0.853 \\
0.854 \\
0.855 \\
0.855\end{array}$ & $\begin{array}{l}0.265 \\
0.225 \\
0.198 \\
0.015 \\
0.004 \\
0.012 \\
0.007 \\
0.001 \\
0.000 \\
0.002 \\
0.000\end{array}$ & $\begin{array}{l}\mathrm{p}<0.0001 \\
\mathrm{p}<0.0001 \\
\mathrm{p}<0.05 \\
\text { NS } \\
\text { NS } \\
\text { NS } \\
\text { NS } \\
\text { NS } \\
\text { NS } \\
\text { NS } \\
\text { NS }\end{array}$ \\
\hline $\begin{array}{l}\text { Number of cigarettes before sample } \\
\text { Minutes since discarding cigarette } \\
\text { Number of cigarettes in last hour } \\
\text { pH of saliva } \\
\text { Daily cigarette consumption } \\
\text { Minutes since last drink } \\
\text { Duration of smoking habit } \\
\text { Time of sample } \\
\text { Urinary nicotine concentration } \\
\text { Nicotine yield of cigarettes }\end{array}$ & $\begin{array}{r}0.623 \\
-0.654 \\
0.588 \\
-0.347 \\
0.539 \\
0.214 \\
0.387 \\
0.078 \\
0.622 \\
0.067\end{array}$ & $\begin{array}{l}0.623 \\
0.750 \\
0.767 \\
0.800 \\
0.809 \\
0.811 \\
0.814 \\
0.818 \\
0.821 \\
0.822\end{array}$ & $\begin{array}{l}0.388 \\
0.174 \\
0.026 \\
0.052 \\
0.015 \\
0.003 \\
0.005 \\
0.006 \\
0.005 \\
0.000\end{array}$ & $\begin{array}{l}\mathrm{p}<0.0001 \\
\mathrm{p}<0.0001 \\
\mathbf{p}<0.05 \\
\mathrm{p}<0.001 \\
\text { NS } \\
\text { NS } \\
\text { NS } \\
\text { NS } \\
\text { NS } \\
\text { NS }\end{array}$ \\
\hline
\end{tabular}

$R=$ Regression. NS $=$ Not significant collected were recorded; it was then deep-frozen until analysed by a gas chromatographic technique.?

Questionnaire-Details of duration of smoking habit, brand of cigarette, whether or not the smoke was inhaled (not at all, slight, medium, or deep), daily cigarette consumption (number smoked before sample collection and the time since last cigarette was finished), time of last meal and last drink, and, for non-smokers, whether or not they had been exposed to another's tobacco smoke while on the way to work, at work, or at a coffee break were elicited from the questionnaires.

\section{Results}

The salivary and urinary nicotine concentrations were significantly correlated for all subjects $(r=0.84)$ (fig 1$)$. The only questionnaire items significantly associated with the nicotine concentrations were the number of cigarettes smoked before sample collection and the number of minutes since the last cigarette was discarded (table I, fig 2). The nicotine yield of the cigarette had no significant influence.

Non-smokers exposed to tobacco smoke in the time before sampling had significantly higher nicotine concentrations than non-exposed 
TABLE II-Mean concentrations of salivary and urinary nicotine in non-smokers according to exposure to tobacco smoke before collection of samples

\begin{tabular}{lccc}
\hline & $\begin{array}{c}\text { Not exposed } \\
(\mathrm{n}=26)\end{array}$ & $\begin{array}{c}\text { Exposed } \\
(\mathrm{n}=30)\end{array}$ & $\begin{array}{c}\text { Significance of } \\
\text { difference }\end{array}$ \\
\hline $\begin{array}{c}\text { Mean urinary } \\
\text { nicotine } \\
\text { concentration } \\
\text { (nmol/1) }\end{array}$ & $46.2( \pm 51 \cdot 2)$ & $133.2( \pm 178 \cdot 2)$ & $\mathrm{F}=11.37 ;$ df $1 / 54 ; \mathrm{p}<0.001$ \\
$\begin{array}{c}\text { Mean salivary } \\
\text { nicotine } \\
\text { concentration } \\
(\mathrm{nmol} / \mathrm{l})\end{array}$ & $36.4( \pm 27 \cdot 1)$ & $62.3( \pm 59 \cdot 8)$ & $\mathrm{F}=5.90 ;$ df $1 / 54 ; \mathrm{p}<0.05$ \\
\hline
\end{tabular}

Conversion: $S I$ to traditional units-Urinary and salivary nicotine: $1 \mathrm{nmol} / 1 \approx 6 \cdot 2$ ng/ml. smoking. For example, ex-smokers who had been exposed to smokers could absorb passively sufficient tobacco smoke to raise their urinary and salivary nicotine concentrations to levels that might refute their claims to have stopped smoking. This could partly account for the high rates of deception reported in previous studies of ex-smokers. ${ }^{14}$

Self-reports of the degree of inhalation were not significantly associated with the concentrations of nicotine in urine and saliva. This confirms previous observations on the lack of reliability of subjective reports of inhalation. ${ }^{15}$ That smokers may regulate their nicotine intake by varying their puffing pattern and depth of inhalation to achieve a desired effect ${ }^{16}{ }^{17}$ is

TABLE III-Mean concentrations ( $\pm 1 S D)$ of nicotine in urine and saliva of smokers according to inhalation characteristics and cigarette consumption before sample was taken

\begin{tabular}{|c|c|c|c|c|c|}
\hline & $\begin{array}{c}\text { Non-inhalers } \\
(n=8)\end{array}$ & $\begin{array}{l}\text { Slight inhalers } \\
(\mathbf{n}=15)\end{array}$ & $\underset{(n=32)}{\text { Medium inhalers }}$ & $\begin{array}{l}\text { Deep inhalers } \\
(\mathrm{n}=27)\end{array}$ & $\begin{array}{l}\text { Significance of } \\
\text { difference }\end{array}$ \\
\hline $\begin{array}{l}\text { Urinary nicotine concentration (nmol/1) } \\
\text { Salivary nicotine concentration (nmol/l) } \\
\text { Cigarette consumption before sample }\end{array}$ & $\begin{aligned} 2455 \cdot 6 & ( \pm 2987 \cdot 7) \\
939 \cdot 0 & ( \pm 964 \cdot 2) \\
2 \cdot 2 & ( \pm 2 \cdot 1)\end{aligned}$ & $\begin{aligned} 7786 \cdot 6 & ( \pm 10947 \cdot 5) \\
2600 \cdot 5 & ( \pm 5622 \cdot 0) \\
4 \cdot 8 & ( \pm 5 \cdot 3)\end{aligned}$ & $\begin{array}{c}8329 \cdot 2( \pm 10538 \cdot 7) \\
2800 \cdot 2( \pm 4526 \cdot 5) \\
5 \cdot 1( \pm 4 \cdot 7)\end{array}$ & $\begin{array}{c}9426 \cdot 6( \pm 9883 \cdot 4) \\
5589 \cdot 4( \pm 8415 \cdot 5) \\
6 \cdot 1( \pm 5 \cdot 6)\end{array}$ & $\begin{array}{l}F=1.3 ; \text { df } 3 / 78 ; \text { NS } \\
F=1.75 ! \text { df } 3 / 78 ; \text { NS } \\
F=2.19 ; \text { df } 3 / 78 ; \text { NS }\end{array}$ \\
\hline
\end{tabular}

Conversion: SI to traditional units-Urinary and salivary nicotine: $1 \mathrm{nmol} / \mathrm{l} \approx 6 \cdot 2 \mathrm{ng} / \mathrm{ml}$.

subjects (table II); these concentrations were similar to those of smokers who smoked up to three cigarettes before sampling (fig 2).

Although the urinary and salivary nicotine concentrations of the smokers appeared to be related to their self-reported inhaling habits, this was not statistically significant (table III), even after the number of cigarettes smoked before sampling had been standardised for.

\section{Discussion}

Nicotine concentrations in saliva and urine were highly correlated. Both of these measures are non-invasive and appear to provide a useful guide to recent exposure to tobacco smoke in smokers and non-smokers.

All non-smokers had detectable concentrations of nicotine in their urine and saliva and half of them had values within the range for cigarette smokers. They were all lifelong non-smokers and none was an ex-smoker, so we have little reason to believe they were covert smokers. This finding suggests that the nonsmokers had absorbed the products of tobacco smoke as a result of passive exposure to smokers during the morning hours before their urine and saliva were sampled. Furthermore, those nonsmokers who reported exposure to tobacco smoke during the morning had significantly higher concentrations of nicotine than those who were not aware of being exposed. We have shown previously that non-smokers can absorb the products of tobacco smoke during periods of intense experimental exposure.1011 In this study the passive exposure occurred under natural conditions during the morning of a typical working day.

The amount of tobacco smoke absorbed by non-smokers can reach concentrations similar to those found after "light" cigarette smoking of up to three cigarettes in the preceding 3-4 hours; this clearly constitutes an unsolicited hazard to their health. Tar intake from passive smoking could be proportionately higher than the intake of nicotine, since sidestream smoke (emitted from the burning tip of a cigarette) contains relatively more tar than mainstream smoke (puffed through the cigarette). ${ }^{12}$ Involuntary smoking by non-smokers may cause disease of the small airways ${ }^{5}$ or increase the risks of lung cancer. ${ }^{6}$ It may also increase the frequency of attacks of angina in patients with ischaemic heart disease. ${ }^{13}$

On a practical level the overlap in nicotine concentrations of smokers and non-smokers makes it difficult to use such measurements to validate claims by ex-smokers that they have given up supported by the lack of significant correlation between the nicotine (and hence tar) yield of the cigarettes and the nicotine concentrations in urine and saliva. Smokers of low-tar (10-16 $\mathrm{mg}$ /cigarette) cigarettes had nicotine concentrations which were similar to those of middle-tar and high-tar smokers. ${ }^{18}$

We thank the Medical Research Council for financial support.

\section{References}

1 Vogt TM, Selvin S, Hulley SB. Comparison of biochemical and questionnaire estimates of tobacco exposure. Prev Med 1979;8:23-33.

2 Commins BT. Measurement of carbon monoxide in the blood: review of available methods. Ann Occup Hyg 1975;18:69-77.

${ }^{3}$ Horan JJ, Hackett G, Linberge SE. Factors to consider when using expired air carbon monoxide in smoking assessment. Addict Behav $1978 ; 3: 25-8$.

4 Russell MAH, Feyerabend C. Cigarette smoking; a dependence on high nicotine boli. Drug Metab Rev 1978;8:29-57.

5 White JR, Froeb HF. Small airways dysfunction in non-smokers chronically exposed to tobacco smoke. $N$ Engl f Med 1980;302:720-3.

${ }^{6}$ Hirayama T. Non-smoking wives of heavy smokers have a higher risk of lung cancer: a study from Japan. $B r$ Med f 1981 ;282:183-5.

${ }^{7}$ Feyerabend C, Russell MAH. Assay of nicotine in biological materials; sources of contamination and their elimination. $f$ Pharm Pharmaco $1980 ; 32: 178-81$.

${ }^{8}$ Draper NR, Smith H. In: Applied regression analysis. Toronto: Wiley, 1967:178-82.

- Armitage P. In: Statistical methods in medical research. Oxford: Blackwell Scientific Publications, 1974:351.

${ }^{10}$ Russell MAH, Feyerabend C. Blood and urine nicotine in non-smokers. Lancet 1975 ; $: 179-81$.

11 Russell MAH, Cole PV, Brown E. Absorption by non-smokers of carbon monoxide from room air polluted by tobacco smoke. Lancet $1973 ; \mathrm{i}: 576-9$.

12 Browne CA, Keith $\mathrm{CH}$, Allen RE. The effect of filter ventilation on the yield and composition of mainstream and sidestream smoke. Beit Tabakforsch 1980;10:81-90.

13 Anonymous. Passive smoking and angina Lancet 1978;ii:413-4.

14 Sillet RW, Wilson MB, Malcolm RE, Ball KP. Deception among smokers. Br Med f 1978; ii:1185-6.

15 Wald N, Idle $M$, Bailey $A$. Carboxyhaemoglobin levels and inhaling habits in cigarette smokers. Thorax $1978 ; 33: 201-6$.

${ }^{16}$ Ashton H, Stepney R, Thompson JW. Self-titration by cigarette smokers. Br Med F 1979;ii:357-60.

17 Russell MAH, Sutton SC, Feyerabend C, Salojee Y. Smokers response to shortened cigarettes: dose reduction without dilution of tobacco smoke. Clin Pharmacol Ther 1980;27:210-8.

${ }^{18}$ Russell MAH, Jarvis M, Iyer R, Feyerabend C. Relation of nicotine yield of cigarettes to blood nicotine concentrations in smokers. $\mathrm{Br} \mathrm{Med} \mathfrak{F}$ $1980 ; 280$ :972-6.

(Accepted 12 fanuary 1982) 